\title{
(2) OPEN ACCESS \\ Characteristics of neonatal herpes simplex virus infections in Germany: results of a 2-year prospective nationwide surveillance study
}

\author{
André Kidszun ำ ${ }^{1,2}$ Anna Bruns, ${ }^{1}$ Daniel Schreiner, ${ }^{1}$ Susanne Tippmann, ${ }^{1}$ \\ Julia Winter, ${ }^{1}$ Roman M Pokora, ${ }^{3}$ Michael S Urschitz (i) , ${ }^{3}$ Eva Mildenberger ${ }^{1}$
}

'Division of Neonatology, Department of Paediatrics, University Medical Centre of the Johannes Gutenberg-University Mainz, Mainz, Rheinland-Pfalz Germany

'Division of Neonatology, Department of Paediatrics, Inselspital, Bern University Hospital, University of Bern, Bern, Switzerland ${ }^{3}$ Division of Paediatric Epidemiology, Institute of Medical Biostatistics, Epidemiology, and Informatics, University Medical Centre of the Johannes Gutenberg-University Mainz, Mainz, Rheinland-Pfalz, Germany

Correspondence to André Kidszun, Division of Neonatology, Department of Paediatrics, Inselspital, Bern University Hospital, University of Bern, Bern, Bern, Switzerland; andre.kidszun@insel.ch

Received 27 February 2021 Accepted 25 June 2021

Check for updates

(C) Author(s) (or their employer(s)) 2021. Re-use permitted under CC BY-NC. No commercial re-use. See rights and permissions. Published by BMJ.

To cite: Kidszun A, Bruns A, Schreiner D, et al. Arch Dis Child Fetal Neonatal Ed Epub ahead of print: [please include Day Month Year] doi:10.1136/

archdischild-2021-321940

\section{ABSTRACT}

Objective To assess incidence and burden of neonatal herpes simplex virus (HSV) infections and to explore possible transmission routes.

Methods A 2-year prospective nationwide surveillance study performed in 2017 and 2018. All German paediatric departments ( $n=464$ in 2017, $n=441$ in 2018) were contacted on a monthly basis to report potential cases of neonatal HSV infections. Infants with a postnatal age of $\leq 60$ days and a positive HSV PCR or HSV culture from skin, mucous membrane, vesicles or conjunctival smear, blood or cerebrospinal fluid were included in the study.

Results 37 cases were analysed. 29 patients who exhibited no or only mild clinical symptoms were discharged home without organ damage or neurological abnormalities. Four patients showed significant neurological impairment, one patient required liver transplantation and two patients died during in-patient treatment. The 2-year incidence of neonatal HSV infections was 2.35 per 100000 live births $(95 \% \mathrm{Cl}$ 1.69 to 3.02 ) and disease-specific mortality was 0.13 per 100000 live births $(95 \% \mathrm{Cl} 0.04$ to 0.21$)$. Data on possible transmission routes were available in 23 cases. In 20 cases, an orofacial HSV infection was present in one or more family members. An active maternal genital HSV infection was reported in 3 cases.

Conclusion Neonatal HSV infections are rare in Germany. Most infants have a benign clinical course, but some infants are severely affected. Postnatal HSV exposure may account for a considerable number of neonatal HSV infections.

\section{INTRODUCTION}

Neonatal herpes simplex virus (HSV) infections are rare. In the USA and Canada, the incidence has been estimated to be around 6-10 cases per 100000 live births. ${ }^{12}$ It is commonly assumed that about $85 \%$ of infants become infected in the intrapartum period, $10 \%$ postnatally and $5 \%$ in utero. However, in many cases, the exact mode of transmission cannot be determined. ${ }^{2}$ Neonatal HSV infections are usually apparent before 14 days of life, but later manifestations have been described.

The two specific types of HSV, HSV-1 and HSV-2, both cause neonatal infections. ${ }^{4}$ Motherto-child transmission is significantly increased in primary versus recurrent maternal infections, during vaginal delivery versus caesarean section and in infection with HSV-1 versus HSV-2. ${ }^{5}$ Maternal

\section{What is already known on this topic?}

- Neonatal herpes simplex virus (HSV) infections are rare but associated with a high morbidity and lethality.

- Maternal genital HSV infection is the most common source of infection.

\section{What this study adds?}

Horizontal transmission via mothers and family members may be a possible source of neonatal HSV infection

- Neonates treated for asymptomatic or skin/ mucous membrane HSV infections have a favourable outcome, while neonates presenting with disseminated disease or eye infection are at high risk for sequelae.

- An urgent need exists for extended HSV serology and direct virus detection in mothers, neonates, and family members to assess perinatal or postnatal HSV transmission.

HSV type-specific serology allows risk-adapted treatment in cases with a high risk of transmission. ${ }^{6}$ In Germany, estimates of HSV seroprevalence in adults are about $78 \%-83 \%$ for HSV-1 and 10\%-13\% for HSV-2. ${ }^{7-9}$ Although seroprevalence has tended to decrease over the past two decades, this decrease may pose a threat to neonates because, concomitantly, susceptibility to HSV infection may increase in the perinatal period. ${ }^{5910}$

Three major disease manifestations of neonatal HSV infection occur: (1) skin, mucosa and conjunctival disease; (2) central nervous system (CNS) disease; (3) disseminated disease with multiple organ involvement. Neonatal HSV infections may present with classic symptoms (herpetic skin and mucosal lesions, seizures), but symptoms may also be nonspecific (fever, poor drinking, lethargy) or absent. ${ }^{11}$ Timely diagnosis is challenging but crucial to avoid a delay in the initiation of antiviral therapy. Neonatal HSV infections can have a high morbidity and mortality. Delayed initiation of therapy has been associated with poorer outcomes. ${ }^{12} 13$ The actual incidence of neonatal HSV infections in Europe, especially in Germany, is insufficiently evaluated. There are also limited data available 
on disease burden, routes of transmission and the frequency of nosocomial neonatal HSV infections. The aim of this study was to assess incidence and burden of neonatal HSV infections and to explore possible transmission routes.

\section{METHODS}

Design

This 2-year prospective nationwide surveillance study was performed in 2017 and 2018. All German paediatric departments $(\mathrm{n}=464$ in $2017, \mathrm{n}=441$ in 2018) were contacted on a monthly basis to report potential cases of neonatal HSV infections. Data were collected via the German Paediatric Surveillance Unit for Rare Diseases (ESPED—in German: Erhebungseinheit für Seltene Pädiatrische Erkrankungen in Deutschland), a voluntary reporting system that covers all German paediatric departments. Following each initial case report, a detailed clinical questionnaire was sent out to the reporting department by ESPED.

The questionnaire included perinatal characteristics, clinical symptoms, diagnostic findings and outcome data. In addition, the questionnaire asked about possible routes of transmission (active maternal genital HSV infection: first or recurring; active non-genital HSV infection: mother, father, siblings, other household members).

\section{Case definition/ inclusion criteria}

Infants with a postnatal age of $\leq 60$ days and a positive HSV PCR or HSV culture from skin, mucous membranes, vesicles or conjunctival smear, blood or cerebrospinal fluid (CSF) were included in the study.

\section{Secondary data sources}

To assess underreporting in the incidence of neonatal HSV infections, an additional dataset was generated using the validated hospital discharge records (coded by the respective ICD-10 code P35.2) reported to the German Federal Statistical Office by the statutory health insurances as the second source. An inquiry was performed for the frequency of the prespecified diagnosis P35.2 "congenital infection due to herpes viruses" in infants with a postnatal age of $\leq 1$ year in the years 2017 and 2018 (data requested from https://www.gbe-bund.de/gbe/; 11 September 2020).

\section{Statistical analysis}

Data entry, cleaning and evaluation were performed using IBM SPSS Statistics V.25. Characteristics of the patients and their mothers were expressed by means for continuous variables and by relative and absolute frequencies for discrete variables.

To estimate the extent to which the ESPED sample was representative, we planned a two-source capture-recapture calculation. Because one of the underlying basic assumptions of a capture-recapture calculation was violated, the distribution of some characteristics was compared with the health insurance data. The numbers of patients were extrapolated to the German live born infants in 2017 and 2018 (Federal Statistical Office, Wiesbaden 2020), and the 2-year incidence of neonatal HSV infections per 100000 live born infants for the years 2017 and 2018 was calculated with $95 \%$ CI. For comparison with the data of our cohort study, we also present the incidence of neonatal HSV infections per 100000 live born infants with the health data reported to the German Federal Statistical Office by the statutory health insurances companies.
Table 1 Perinatal characteristics of neonates with HSV infection in Germany 2017-2018

\begin{tabular}{|c|c|}
\hline Infant's characteristics & $\mathrm{N}$ \\
\hline Total & 37 \\
\hline \multicolumn{2}{|l|}{ Sex } \\
\hline Male & 20 \\
\hline Female & 17 \\
\hline \multicolumn{2}{|l|}{ Gestation } \\
\hline Term & 29 \\
\hline Preterm & 7 \\
\hline N/A & 1 \\
\hline \multicolumn{2}{|l|}{ Age at onset of symptoms* } \\
\hline Day of life, median (min, max) & $10(0,52)$ \\
\hline \multicolumn{2}{|c|}{ Days between onset of symptoms and start of antiviral treatment* } \\
\hline Days, median (min, max) & $2(0,13)$ \\
\hline \multicolumn{2}{|l|}{ Mother's characteristics } \\
\hline Totalt & 36 \\
\hline \multicolumn{2}{|l|}{ Maternal age, years } \\
\hline $20-35$ & 30 \\
\hline$>35$ & 2 \\
\hline$<20$ & 4 \\
\hline \multicolumn{2}{|l|}{ Birth mode } \\
\hline Vaginal & 22 \\
\hline Vaginal-instrumental & 4 \\
\hline Caesarean section & 4 \\
\hline N/A & 6 \\
\hline \multicolumn{2}{|c|}{ Rupture of membranes $>18$ hours before birth } \\
\hline Yes & 2 \\
\hline No & 16 \\
\hline N/A & 18 \\
\hline
\end{tabular}

*Available for the $27 / 37$ infants that were symptomatic.

tTotal number is 36 for the mothers since a pair of twins was included in the survey. For child-related factors, this mother is included in the calculations for each child individually.

HSV, herpes simplex virus; N/A, not applicable.

\section{RESULTS}

\section{Incidence}

There were 48 initially reported cases in 2017 and 2018. The case definition was not fulfilled in three cases, and in another eight cases the questionnaires were not sent back. Thus, a total of 37 affected infants, including one pair of twins, were analysed. Perinatal characteristics are presented in table 1 . The 2-year incidence of neonatal HSV infections was 2.35 per 100000 live births (95\% CI 1.69 to 3.02). This result was in line with the health data reported to the German Federal Statistical Office by the statutory health insurance companies. Retrospective analysis of the period from 2017 to 2018 resulted in 60 cases with a diagnosis of "congenital infection due to herpes viruses". This corresponded to an incidence of 3.83 per 100000 live births.

\section{Distribution of HSV subtypes}

In most cases (18 infants), infection with HSV type 1 was present. Type 2 was detected in four infants, and mixed infection with HSV types 1 and 2 occurred in two infants. In the remaining 13 cases, no subtype determination was performed, or the result was unknown. HSV subtype 2, which is associated with genital herpes, CNS infection or disseminated infection in adults, was exclusively detected in infants with eye infection. HSV subtype 1 was present in all types of infections. 


\section{Antiviral therapy}

Therapy of all neonatal HSV infections was with acyclovir, with doses ranging from 13 to $70 \mathrm{mg} / \mathrm{kg} /$ day. In two infants, the doses were not reported. The duration of therapy ranged from 4 to 205 days, with a median of 14 days. In two infants, the duration of therapy was not reported.

\section{Hospital stays}

Most infants (28) were solely treated on general paediatric wards while 8 infants received treatment in intensive care units. The median duration of hospital stay was 14 days, with a minimum of 2 days and a maximum of 73 days. Length of hospital stays and inpatient assignment were not reported for two patients each.
Possible transmission routes and risk factors

Data on possible transmission routes were available for 23 infants. In 20 cases, an orofacial HSV infection was present in one or more family members (mothers in 15 cases, fathers in 3 cases, both parents in 1 case and a sibling in 1 case). Labial herpes was reported in 17 cases, one mother was affected by nasal herpes and another had periorbital herpes. In one case, a mother of affected twins had labial herpes.

An active genital HSV infection was reported from three mothers. Twenty-six mothers definitely did not reveal symptoms of a genital HSV infection, while the status was unknown in seven mothers. None of the mothers was reported to have been treated with acyclovir before or during delivery to prevent transmission of the herpes virus.

\begin{tabular}{|c|c|c|c|c|c|c|}
\hline Case number & $\begin{array}{l}\text { Onset of symptoms } \\
\text { (DOL) }\end{array}$ & $\begin{array}{l}\text { Hospitalisation since } \\
\text { birth }\end{array}$ & $\begin{array}{l}\text { Localisation of HSV } \\
\text { detection* }\end{array}$ & HSV subtype & HSV copies/mL & $\begin{array}{l}\text { Active maternal or household } \\
\text { HSV infection }\end{array}$ \\
\hline 1 & 6 & No & CSF & 2 & N/A & Mother, labial herpes \\
\hline 2 & 5 & No & CSF & 1 & N/A & None reported \\
\hline 3 & 30 & No & CSF & 1 & N/A & Mother, labial herpes \\
\hline 4 & $\mathrm{~N} / \mathrm{A}$ & Yes & Mucocutaneous & $\mathrm{N} / \mathrm{A}$ & N/A & Mother, labial herpes \\
\hline 5 & 5 & No & CSF & 2 & $\mathrm{~N} / \mathrm{A}$ & None reported \\
\hline 6 & 1 & Yes & Blood & 1 & $5.8 \times 10^{2}$ & Mother, labial herpes \\
\hline 7 & 18 & No & Blood & N/A & $N / A$ & None reported \\
\hline $8 \dagger$ & $\mathrm{N} / \mathrm{A}$ & Yes & Mucocutaneous & $\mathrm{N} / \mathrm{A}$ & N/A & Mother, labial herpes \\
\hline $9 \dagger$ & N/A & Yes & Mucocutaneous & N/A & N/A & Mother, labial herpes \\
\hline 10 & $\mathrm{~N} / \mathrm{A}$ & Yes & Mucocutaneous & $\mathrm{N} / \mathrm{A}$ & N/A & $\begin{array}{l}\text { Mother, various mucocutaneous } \\
\text { lesions }\end{array}$ \\
\hline 11 & 6 & No & Blood & N/A & N/A & None reported \\
\hline 12 & N/A & Yes & Mucocutaneous & N/A & N/A & Mother, labial herpes \\
\hline 13 & 19 & No & Blood & $\mathrm{N} / \mathrm{A}$ & $\mathrm{N} / \mathrm{A}$ & Father, labial herpes \\
\hline 14 & 3 & Yes & Blood & 1 & $5 \times 10^{6}$ & None reported \\
\hline 15 & 2 & Yes & Mucocutaneous & 1 & $N / A$ & Father, labial herpes \\
\hline 16 & 34 & No & Blood & 1 & $\mathrm{~N} / \mathrm{A}$ & Mother, labial herpes \\
\hline 17 & 7 & No & Mucocutaneous & 1 & $\mathrm{~N} / \mathrm{A}$ & Mother, labial herpes \\
\hline 18 & 21 & No & CSF & 1 & $4.3 \times 10^{2}$ & None reported \\
\hline 19 & 13 & No & Mucocutaneous & 1 & $N / A$ & Father, labial herpes \\
\hline 20 & 9 & No & Mucocutaneous & 1 & N/A & Mother, labial herpes \\
\hline 21 & 52 & No & Mucocutaneous & N/A & N/A & Sibling, labial herpes \\
\hline 22 & 3 & No & CSF & 2 & $\mathrm{~N} / \mathrm{A}$ & None reported \\
\hline 23 & 2 & Yes & Blood & 1 & $4.5 \times 10^{6}$ & None reported \\
\hline 24 & 6 & No & Mucocutaneous & 1 & $\mathrm{~N} / \mathrm{A}$ & None reported \\
\hline 25 & 9 & No & CSF & 2 & $5.7 \times 10^{3}$ & None reported \\
\hline 26 & 21 & No & Mucocutaneous & 1 & $\mathrm{~N} / \mathrm{A}$ & None reported \\
\hline 27 & 0 & Yes & Mucocutaneous & 1 & N/A & None reported \\
\hline 28 & 8 & Yes & Blood & 1 & N/A & None reported \\
\hline 29 & N/A & Yes & Mucocutaneous & 1 & N/A & Mother, genital herpes \\
\hline 30 & $\mathrm{~N} / \mathrm{A}$ & No & Mucocutaneous & 1 & $\mathrm{~N} / \mathrm{A}$ & Mother, labial herpes \\
\hline 31 & 14 & No & Mucocutaneous & 1 & $6.7 \times 10^{3}$ & Mother, labial herpes \\
\hline 32 & $\mathrm{~N} / \mathrm{A}$ & No & Mucocutaneous & N/A & $\mathrm{N} / \mathrm{A}$ & $\begin{array}{l}\text { Mother, various mucocutaneous } \\
\text { lesions }\end{array}$ \\
\hline 33 & N/A & No & Mucocutaneous & 1 and 2 & N/A & Mother, genital herpes \\
\hline 34 & $\mathrm{~N} / \mathrm{A}$ & No & Mucocutaneous & $\mathrm{N} / \mathrm{A}$ & $\mathrm{N} / \mathrm{A}$ & Mother, labial herpes \\
\hline 35 & 12 & No & Mucocutaneous & N/A & N/A & None reported \\
\hline 36 & 35 & No & Mucocutaneous & $\mathrm{N} / \mathrm{A}$ & $\mathrm{N} / \mathrm{A}$ & Mother, labial herpes \\
\hline 37 & 25 & No & Blood & 1 and 2 & $\mathrm{~N} / \mathrm{A}$ & Mother, genital herpes \\
\hline
\end{tabular}

*All tests performed via PCR.

†Twins.

CSF, cerebrospinal fluid; DOL, day of life; HSV, herpes simplex virus; N/A, not available. 
Table 3 Clinical and diagnostic characteristics of neonates with HSV infection in Germany 2017-2018

\begin{tabular}{|c|c|}
\hline Category of disease & Number of infants* \\
\hline Mucocutaneous & 21 \\
\hline Eye & 8 \\
\hline CNS & 2 \\
\hline Disseminated & 4 \\
\hline Not reported & 2 \\
\hline \multicolumn{2}{|l|}{ Clinical symptoms } \\
\hline No symptoms & 10 \\
\hline Mucocutaneous herpes blisters & 10 \\
\hline Poor feeding & 7 \\
\hline Circulatory problems & 7 \\
\hline Body temperature $>38.0^{\circ} \mathrm{C}$ & 5 \\
\hline Seizures & 6 \\
\hline Dyspnoea or tachypnoea & 6 \\
\hline Apnoea & 5 \\
\hline Lethargy & 4 \\
\hline Unspecific symptoms & 6 \\
\hline \multicolumn{2}{|l|}{ Laboratory findings } \\
\hline No abnormal findings & 21 \\
\hline Elevated liver enzymes & 10 \\
\hline Leucocyte count >15/nL & 7 \\
\hline Thrombocytopenia $<150 / n L$ & 5 \\
\hline Abnormal coagulation & 4 \\
\hline $\mathrm{CRP}>15 \mathrm{mg} / \mathrm{L}$ & 4 \\
\hline CSF cell count $>20 / n L(0-28$ DOL), $>9 / n L(29-60$ DOL) & 3 \\
\hline CSF glucose $<40 \mathrm{mg} / \mathrm{dL}$ & 2 \\
\hline Leucocyte count <5/nL & 1 \\
\hline \multicolumn{2}{|l|}{ Diagnostics } \\
\hline \multicolumn{2}{|l|}{ Cranial ultrasound } \\
\hline Normal & 23 \\
\hline Abnormal & 4 \\
\hline Not performed/unknown & 10 \\
\hline \multicolumn{2}{|l|}{ Cranial MRI } \\
\hline Normal & 3 \\
\hline Abnormal & 5 \\
\hline Not performed & 29 \\
\hline \multicolumn{2}{|l|}{ EEG } \\
\hline Normal & 2 \\
\hline Abnormal & 6 \\
\hline Not performed & 29 \\
\hline
\end{tabular}

*Multiple answers possible.

CNS, central nervous system; CRP, C reactive protein; CSF, cerebrospinal fluid; DOL, day of life; EEG, electroencephalogram; HSV, herpes simplex virus.

Table 2 summarises the virological profiles of the affected infants and their families.

\section{Clinical symptoms and outcomes}

During the study period, two deaths associated with neonatal HSV infection were reported. One of those infants was also diagnosed with an inborn error of metabolism, likely contributing to the fatal outcome. The two deaths resulted in a case fatality rate of $5.4 \%(95 \%$ CI 1.37 to 6.97$)$ and a disease-specific mortality rate of 0.13 per 100000 live births $(95 \%$ CI 0.04 to 0.21$)$.

Ten infants were asymptomatic. Fifteen infants presented with one isolated symptom and 12 infants presented with a combination of two to five symptoms. Details on disease manifestation and symptoms are given in table 3 .
Twenty-nine infants were healthy at discharge, while five infants had significant sequelae. Four of them showed significant neurological impairment, and one had a liver transplant. In one case, the outcome was unknown, as the infant was transferred to another hospital without further information available. Half of the infants who presented with disseminated disease had sequelae, as did $37.5 \%$ of those with eye infection. Almost all $(97.3 \%)$ infants with a skin or mucous membrane lesion and all asymptomatic infants were healthy at discharge.

\section{DISCUSSION}

The incidence of neonatal HSV infections has been previously estimated to range from 1.4 to 4.7 per 100000 live births in Switzerland, Australia and the Netherlands ${ }^{14-17}$; and up to 5.9, 8.4 and 12.1 per 100000 live births in Canada, Israel and the USA. ${ }^{218} 19$ Globally, the incidence is estimated to be around 10 per 100000 live births. ${ }^{20}$ We report an incidence at the lower end of this spectrum for Germany (2.35 per 100 000). The different study results appear comparable, even though study designs and definitions of neonatal HSV infection vary across studies. Differences between regions and countries are largely unknown but are likely attributable to cultural differences or differences in primary healthcare settings. Compared with other studies, reporting case fatality rates of $19 \%$ to $26 \%$, death from neonatal HSV infection was low in our study. ${ }^{1721}$

It is commonly assumed that most neonatal HSV infections occur in the intrapartum period and that postnatal transmissions are rare incidents. ${ }^{3} 1422$ However, HSV transmission routes have been insufficiently evaluated in prospective studies. As with incidence, transmission routes may also vary significantly between countries and regions. In our study, symptoms of maternal genital HSV infections were rarely reported, while non-genital HSV infections of household members were frequent among affected neonates. Possible postnatal transmission of HSV via household members has been suggested in various case reports ${ }^{23-28}$ and also in one large study from Jones et al. ${ }^{17}$ Our study supports this suggestion, but cannot definitely prove this mode of transmission due to lack of molecular testing. Future studies will need to incorporate comprehensive maternal antibody testing and molecular genetic techniques to explore preventive factors and to further elucidate sources of neonatal HSV infections.

HSV-1 was detected in the majority of infections. This is in contrast to high maternal and neonatal HSV-2 infection rates in other parts of the world. ${ }^{20}$ These results indicate regional differences in the epidemiology of neonatal HSV infections. In Germany, it appears that awareness of maternal genital HSV infections is high, and that prenatal care may have improved over time, while postnatal HSV exposure may be more common. However, vertical transmission may have been underestimated in this study since transmission occurring in the birth canal is also possible in the absence of active genital HSV lesions. ${ }^{29}$ HSV shedding around birth can also occur with asymptomatic reactivation and only be estimated adequately, if direct virus monitoring is performed in particular on the basis of previously reported episodes of genital $\mathrm{HSV}^{4}$

Our study adds evidence to the possibility of postnatal HSV exposure. Neonates are at risk of acquiring HSV infections from family members or others with skin or mucous membrane infections. More research is needed to evaluate strategies of empirical antiviral therapy of exposed infants, including those with no or mild symptoms. Based on the available evidence, families should receive comprehensive counselling, and preventive measures, 
especially avoidance of contact with herpetic blisters, should be liberally implemented. ${ }^{30}$

We found seven infants with serious adverse outcomes. Our findings that infants with skin/mucous membrane infection commonly had good outcome at discharge, but that many infants with disseminated disease had sequelae, warrant further confirmatory investigations. However, we suggest that parents of infants presenting with no or only mild symptoms and who are on antiviral treatment may be reassured.

In summary, neonatal HSV infections are rare in Germany. The vast majority of infections are skin/mucous membrane infections with a mild clinical course and very good outcome. Nevertheless, HSV infections can be extremely severe in individual cases and cause permanent severe impairment. Horizontal infection within the family may be a possible transmission route. Neonatal HSV infection is for both mothers and infants, as well as family members, an interdisciplinary diagnosis. Inclusion of specific maternal and infant virological data is a prerequisite for urgently needed multi-national studies to increase our knowledge on recognition and prevention of neonatal HSV infections.

Acknowledgements The authors wish to thank Professor Fred Zepp who generously supported the study. Study results are part of the doctoral thesis of one coauthor (AB).

Contributors AK: conceived the idea of the study, coordinated and supervised data collection, evaluated the analyses, and drafted the initial and the revised manuscript. AB: participated in data collection, carried out the statistical analyses and critically reviewed the manuscript. DS: evaluated the analyses and critically reviewed the manuscript. ST: supervised data collection, evaluated the analyses and critically reviewed the manuscript. JW: evaluated the analyses and critically reviewed the manuscript. RMP: participated in data collection, supervised the statistical analyses, and critically reviewed and revised the manuscript. MSU: supervised the statistical analyses and critically reviewed the manuscript. EM: conceptualised, designed and supervised the study, and critically reviewed the manuscript. All authors approved the final manuscript as submitted and agree to be accountable for all aspects of the work.

Funding The authors have not declared a specific grant for this research from any funding agency in the public, commercial or not-for-profit sectors.

Competing interests None declared.

Patient consent for publication Not required.

Ethics approval The local Ethics Committee of the Rhineland-Palatinate Medical Association (Ethik-Kommission der Landesärztekammer Rheinland Pfalz), Mainz, Germany (reference number 837.005.17) approved this study. A waiver of written informed consent was granted as participants were not subjected to any studyrelated procedures and data were collected in an anonymised way.

Provenance and peer review Not commissioned; externally peer reviewed.

Data availability statement Data are available on reasonable request.

Open access This is an open access article distributed in accordance with the Creative Commons Attribution Non Commercial (CC BY-NC 4.0) license, which permits others to distribute, remix, adapt, build upon this work non-commercially, and license their derivative works on different terms, provided the original work is properly cited, appropriate credit is given, any changes made indicated, and the use is non-commercial. See: http://creativecommons.org/licenses/by-nc/4.0/.

\section{ORCID iDs}

André Kidszun http://orcid.org/0000-0002-9329-6802

Michael S Urschitz http://orcid.org/0000-0002-7906-9427

\section{REFERENCES}

1 Flagg EW, Weinstock $\mathrm{H}$. Incidence of neonatal herpes simplex virus infections in the United States, 2006. Pediatrics 2011;127:e1-8.

2 Kropp RY, Wong T, Cormier L, et al. Neonatal herpes simplex virus infections in Canada: results of a 3-year national prospective study. Pediatrics 2006;117:1955-62.

3 Kimberlin DW, Baley J, et al, Committee on Infectious Diseases. Guidance on management of asymptomatic neonates born to women with active genital herpes lesions. Pediatrics 2013;131:383-6.

4 James SH, Kimberlin DW. Neonatal herpes simplex virus infection: epidemiology and treatment. Clin Perinatol 2015:42:47-59.

5 Brown ZA, Wald A, Morrow RA, et al. Effect of serologic status and cesarean delivery on transmission rates of herpes simplex virus from mother to infant. JAMA 2003;289:203-9.

6 Robinson JL, Vaudry WL, Forgie SE, et al. Prevention, recognition and management of neonatal HSV infections. Expert Rev Anti Infect Ther 2012;10:675-85.

7 Wutzler P, Doerr HW, Färber I, et al. Seroprevalence of herpes simplex virus type 1 and type 2 in selected German populations - relevance for the incidence of genital herpes. J Med Virol 2000;61:201-7.

8 Hellenbrand W, Thierfelder W, Müller-Pebody B, et al. Seroprevalence of herpes simplex virus type 1 (HSV-1) and type 2 (HSV-2) in former East and West Germany, 1997-1998. Eur J Clin Microbiol Infect Dis 2005;24:131-5.

9 Korr G, Thamm M, Czogiel I, et al. Decreasing seroprevalence of herpes simplex virus type 1 and type 2 in Germany leaves many people susceptible to genital infection: time to raise awareness and enhance control. BMC Infect Dis 2017;17:471.

10 Kimberlin DW. The Scarlet H. J Infect Dis 2014;209:315-7.

11 Curfman AL, Glissmeyer EW, Ahmad FA, et al. Initial presentation of neonatal herpes simplex virus infection. J Pediatr 2016;172:121-6.

12 Enright AM, Prober CG. Neonatal herpes infection: diagnosis, treatment and prevention. Semin Neonatol 2002;7:283-91.

13 Shah SS, Aronson PL, Mohamad Z, et al. Delayed acyclovir therapy and death among neonates with herpes simplex virus infection. Pediatrics 2011;128:1153-60.

14 Pascual A, Moessinger A, Gerber S, et al. Neonatal herpes simplex virus infections in Switzerland: results of a 6-year national prospective surveillance study. Clin Microbiol Infect 2011;17:1907-10.

15 Hemelaar SJAL, Poeran J, Steegers EAP, et al. Neonatal herpes infections in The Netherlands in the period 2006-2011. J Matern Fetal Neonatal Med 2015;28:905-9.

16 Poeran J, Wildschut H, Gaytant M, et al. The incidence of neonatal herpes in The Netherlands. J Clin Virol 2008;42:321-5.

17 Jones CA, Raynes-Greenow C, Isaacs D, et al. Population-based surveillance of neonatal herpes simplex virus infection in Australia, 1997-2011. Clinical Infectious Diseases 2014:59:525-31

18 Koren A, Tasher D, Stein M, et al. Neonatal herpes simplex virus infections in Israel. Pediatr Infect Dis J 2013:32:120-3.

19 Morris SR, Bauer HM, Samuel MC, et al. Neonatal herpes morbidity and mortality in California, 1995-2003. Sex Transm Dis 2008:35:14-18.

20 Looker KJ, Magaret AS, May MT, et al. First estimates of the global and regional incidence of neonatal herpes infection. Lancet Glob Health 2017;5:e300-9.

21 Lopez-Medina E, Cantey JB, Sánchez PJ. The mortality of neonatal herpes simplex virus infection. J Pediatr 2015;166:1529-32.

22 Corey L, Wald A. Maternal and neonatal herpes simplex virus infections. N Engl J Med 2009;361:1376-85.

23 Renk H, Hartleif S, Hamprecht K. Disseminated neonatal herpes simplex virus infection: postnatal acquisition and familial spread during migration to Germany. Travel Med Infect Dis 2019:29:75-7.

24 Linnemann C, Buchman TG, Light IJ. Transmission of herpes-simplex virus type 1 in a nursery for the newborn. Identification of viral isolates by D.N.A. "fingerprinting.". Lancet 1978;311:964-6.

25 Bal A, Zandotti C, Nougairede A, et al. Fulminant hepatitis due to father-to-newborn transmission of herpes simplex virus type 1. Open Virol J 2013;7:96-7.

26 Guergué Diaz de Cerio O, Rubio Lombraña M, Barrutia Borque A, et al. Father-tonewborn transmission of herpes simplex virus infection: a sweet but bitter kiss. Actas Dermosifiliogr 2016;107:797-8.

27 Field SS. Fatal neonatal herpes simplex infection likely from unrecognized breast lesions. J Hum Lact 2016;32:86-8.

28 Mann E, Pitt M, McAllister S. Biting cousins — disseminated neonatal herpes simplex virus infection from a human bite. J Pediatr 2016;169:328-328.e1.

29 Kimberlin DW. Neonatal herpes simplex infection. Clin Microbiol Rev 2004;17:1-13.

30 Pittet LF, Curtis N. Postnatal exposure to herpes simplex virus: to treat or not to treat? Pediatr Infect Dis J 2021;40. 